\title{
SISTEM INSTALASI PENGOLAHAN AIR-LIMBAH (IPAL) KOMUNAL DI RW 11 KELURAHAN KERTAJAYA KECAMATAN GUBENG SURABAYA Aditya Wijaya, Didik Sugeng Purwanto, Supriyandani
}

\begin{abstract}
Urban sanitation remained a difficult problem to overcome, particularly waste water management. Improper wastewater discharges that do not meet health and environmental requirements maybe harmful to health . In order to control discharges of domestic wastewater, the Governor of East Java issued Regulation No. 72 of 2013 regarding Wastewater Standard for Industries and/or Other Business Activities that includes parameters such as $\mathrm{pH}, \mathrm{BOD}, \mathrm{COD}, \mathrm{TSS}$, Oils and Fats. The purpose of the present study was to determine the system and processes of communal WWTP in RT 4 RW 11 on Jalan Kertajaya IV Raya Kelurahan Kertajaya Kecamatan Gubeng of Surabaya Municipality.

This was a descriptive and cross-sectional study. Data were collected through observations, measurements, interviews, laboratory tests, as well as secondary data collection. Water samples were taken three times at the inlet and outlet of the WWTP. The collected data were subsequently analyzed in descriptive manner.

Results showed that the inflow was greater than the outflow, leading to overflow of the WWTP. Sources of wastewater consisted of domestic wastewater, water used to wash utilities, water discharge from motor vehicles washing activities. Wastewater was treated by biological method consisted of an anaerobic system and physical methods involving a filtration system. Wastewater was sampled at the inlet and outlet points of the WWTP using a time-combination method. BOD removal efficiency was found to be $29.9 \%-67.9 \%$; COD removal efficiency was $8.5 \%-44.6 \%$; TSS removal efficiency was $41.7 \%-92.3 \%$; Oil and Fat removal efficiency was 5\%$61.9 \%$. The quality of treated domestic wastewater of RW 11 Kelurahan Kertajaya did not meet the designated requirements with regard to parameters of BOD, COD, Oil and Fat.

It is recomended to improve the processing capacity of the WWTP in order to prevent overflows, increase the dimension of the biological treatment facility, and add a grease trap unit to help the effluent quality to meet the standards stated in East Java Governor Regulation No. 72 of 2013.
\end{abstract}

\section{Keywords: domestic wastewater; communal WWTP; removal efficiency}

\section{PENDAHULUAN}

Sanitasi perkotaan merupakan masalah yang sulit untuk diatasi, khususnya pengelolaan air limbah. Menurut Purwanto (2006), timbulnya masalah air limbah ini dikarenakan pertambahan penduduk di perkotaan yang semakin pesat dan tidak diimbangi dengan adanya sarana sanitasi yang memadai guna mengatasi air limbah dari masyarakat perkotaan, karena minimnya Instalasi Pengolahan Air Limbah (IPAL) secara komunal.

Menurut Purwanto (2010), dampak pembuangan air limbah yang tidak memenuhi syarat terhadap kesehatan dan lingkungan adalah gangguan terhadap pandangan dan bau (gangguan estetika), terjadinya genangan air limbah yang akan menjadikan tempat perkembangbiakan serangga dan nyamuk, serta terjadinya pencemaran air permukaan serta pencemaran air tanah. Untuk mencegah terjadinya pencemaran lingkungan, diperlukan upaya yang tepat dalam memilih lokasi pembuangan dan cara pengolahannya.

Menurut Kementerian Pekerjaan Umum dalam Pelatihan Tenaga Fasilitator Lapangan Sanimas Teknologi Sanitasi (2006), IPAL komunal yaitu berupa sistem perpipaan yang mengalirkan air limbah dari rumah tangga yang tersambung dengan sistem perpipaan dan pengolahannya dilakukan secara terpusat. Perawatan jaringan perpipaan dan pengurasan lumpur bekas olahan IPAL, secara periodik harus dibersihkan dan dikuras, sehingga perlu dikelola oleh kelompok swadaya masyarakat setempat. 
Penerapan IPAL secara komunal telah dilakukan oleh warga di Jalan Kertajaya IV Raya RT 4 RW 11 Kelurahan Kertajaya Kecamatan Gubeng Kota Surabaya untuk kategori grey water, yaitu air bekas cucian dapur, mesin cuci, dan kamar mandi, sedangkan air yang telah tercampur urin atau tinja manusia termasuk dalam kategori black water (Asmadi dan Suharno, 2012). Di awal tahun 2012, RW 11 Kelurahan Kertajaya ikut berpartisipasi program Pemkot Surabaya dalam lomba SCGC 2012 atau lebih dikenal dengan Surabaya Cantik Green and Clean Tahun 2012 dalam kategori Kampung Berkembang, dan berhasil mendapatkan Sertifikat Instalasi Pengolahan Air Limbah (IPAL) terbaik seluruh Surabaya.

Untuk mengontrol buangan air limbah domestik, Gubernur Jawa Timur mengeluarkan Peraturan Gubernur Jawa Timur Nomor 72 Tahun 2013 Tentang Baku Mutu Air Limbah Bagi Industri Dan/Atau Kegiatan Usaha Lainnya yang terdiri dari parameter $\mathrm{pH}$, BOD, COD, TSS, serta Minyak dan Lemak.

Tujuan penelitian ini adalah untuk mengetahui sistem dan proses IPAL komunal di Jalan Kertajaya IV Raya RT 4 RW 11 Kelurahan Kertajaya Kecamatan Gubeng Kota Surabaya.

\section{METODE PENELITIAN}

Jenis penelitian ini termasuk deskriptif yaitu menggambarkan sistem dan proses IPAL komunal di Jalan Kertajaya IV Raya RT 4 RW 11 Kertajaya-Gubeng Kota Surabaya.
Sedangkan berdasarkan waktu penelitian, termasuk dalam penelitian cross sectional dimana pengambilan contoh air limbah pada inlet dan outlet dilakukan dalam waktu bersamaan.

Objek penelitian adalah pada IPAL komunal di Jalan Kertajaya IV Raya RT 4 RW 11 Kelurahan Kertajaya Kecamatan Gubeng Kota Surabaya. Sampel/contoh uji dalam penelitian ini adalah air limbah domestik dari warga yang diolah di IPAL di Jalan Kertajaya IV Raya RT 4 RW 11 Kelurahan Kertajaya Kecamatan Gubeng Kota Surabaya. Pengambilan contoh menggunakan pengulangan sebanyak tiga kali. Variabel yang diteliti pada penelitian ini adalah (a) debit air limbah per hari, (b) parameter $\mathrm{pH}, \mathrm{BOD}, \mathrm{COD}$, TSS, Minyak dan Lemak, dan (c) efisiensi removal.

Sumber data berasal dari (a) data primer yaitu dengan pengukuran, observasi, wawancara, pemeriksaan laboratorium, dan (b) data sekunder.

Data dianalisis secara deskriptif, yaitu dengan perbandingan dan pedoman Perda.

\section{HASIL PENELITIAN DAN PEMBAHASAN}

\section{Debit Air Limbah}

Debit air limbah pada inlet didapatkan dari hasil obsevasi yaitu pada waktu pagi ( 4 jam), siang ( 3 jam), dan sore ( 4 jam) dikarenakan pada jam-jam tersebut air limbah diproduksi oleh rumah tangga. Dari pengukuran dan perhitungan yang telah dilakukan, diketahui debit pada in/et adalah 30,81 $\mathrm{m}^{3} /$ hari.

Tabel 1

HASIL PENGUKURAN DEBIT AIR LIMBAH

PADA INLETIPAL RW 11 KELURAHAN KERTAJAYA TAHUN 2014

\begin{tabular}{|c|c|c|c|c|c|}
\hline \multirow[t]{2}{*}{ No. } & \multirow{2}{*}{$\begin{array}{c}\text { Waktu } \\
\text { Pengukuran }\end{array}$} & \multicolumn{3}{|c|}{$\begin{array}{c}\text { Debit In/et } \\
\text { (liter/menit) }\end{array}$} & \multirow{2}{*}{$\begin{array}{c}\text { Debit } \\
\text { Rata-Rata } \\
\text { (liter/menit) }\end{array}$} \\
\hline & & $\mathbf{I}$ & II & III & \\
\hline \multicolumn{6}{|c|}{ Pengukuran I (Selasa, 15 Juli 2014) } \\
\hline 1. & Pagi & 46,18 & 45,84 & 46,46 & 46,16 \\
\hline 2. & Siang & 44,74 & 44,64 & 45,22 & 44,87 \\
\hline 3. & Sore & 48,12 & 48,32 & 47,78 & 48,07 \\
\hline \multicolumn{6}{|c|}{ Pengukuran II (Kamis, 17 Juli 2014) } \\
\hline 4. & Pagi & 46,68 & 46,16 & 46,40 & 46,41 \\
\hline 5. & Siang & 45,06 & 45,24 & 45,24 & 45,18 \\
\hline 6. & Sore & 48,50 & 48,44 & 48,38 & $48,4 \overline{4}$ \\
\hline \multicolumn{6}{|c|}{ Pengukuran III (Sabtu, 19 Juli 2014) } \\
\hline 7. & Pagi & 45,32 & 45,32 & 46,08 & 45,57 \\
\hline 8. & Siang & 46,16 & 46,18 & 46,30 & 46,21 \\
\hline 9. & Sore & 48,24 & 47,70 & 48,74 & 48,23 \\
\hline \multicolumn{5}{|c|}{ Rata-Rata Debit } & 46,57 \\
\hline
\end{tabular}


Berdasarkan wawancara kepada penjaga IPAL, IPAL komunal milik RW 11 hanya dioperasikan selama 2 jam setiap harinya disaat sore hari pada musim kemarau saja, yaitu untuk menyirami tanaman maupun menyiram jalan.

Dari pengukuran dan perhitungan yang telah dilakukan, diketahui kapasitas outlet adalah $1,97 \mathrm{~m}^{3} /$ hari, yang artinya kapasitas pengolahan IPAL komunal milik RW 11 tidak seimbang, yaitu kapasitas air limbah yang dihasilkan lebih besar dari pada kapasitas pengolahan IPAL, sehingga IPAL komunal milik RW 11 menjadi overflow. Menurut Rochman (2009), Dalam menyusun IPAL, sistem harus kontinyu dan pengaturan kecepatan alir harus konstan sedemikian rupa sehingga tidak timbul overflow.

Tabel 2 DEBIT AIR LIMBAH PADA OUTLETIPAL RW 11 KERTAJAYA TAHUN 2014

\begin{tabular}{|c|c|c|c|c|c|}
\hline \multirow[t]{2}{*}{ No. } & \multirow{2}{*}{$\begin{array}{c}\text { Waktu } \\
\text { Pengukuran }\end{array}$} & \multicolumn{3}{|c|}{$\begin{array}{l}\text { Debit Out/et } \\
\text { (liter/menit) }\end{array}$} & \multirow{2}{*}{$\begin{array}{c}\text { Debit } \\
\text { Rata-Rata (liter/menit) }\end{array}$} \\
\hline & & I & II & III & \\
\hline \multicolumn{6}{|c|}{ Pengukuran I (Selasa, 15 Juli 2014) } \\
\hline 1. & Sore & 16,52 & 16,34 & 16,64 & 16,50 \\
\hline \multicolumn{6}{|c|}{ Pengukuran II (Kamis, 17 Juli 2014) } \\
\hline 2. & Sore & 16,40 & 15,98 & 16,28 & 16,22 \\
\hline \multicolumn{6}{|c|}{ Pengukuran III (Sabtu, 19 Juli 2014) } \\
\hline 3. & Sore & 16,56 & 16,36 & 16,40 & 16,44 \\
\hline \multicolumn{5}{|c|}{ Rata-Rata Debit } & 16,38 \\
\hline
\end{tabular}

\section{Sumber Air Limbah Warga RW 11}

Berdasarkan hasil observasi dan wawancara dengan penanggung jawab IPAL, warga RT 4 dan warga RT 6 yang air limbahnya diolah di IPAL, didapatkan hasil sumber air limbah yang diolah pada IPAL, terdiri dari:

1. Air Bekas Cuci Pakaian: Mengandung surfaktan dan padatan tersuspensi.
2. Air Bekas Cuci Piring: Mengandung padatan tersuspensi, minyak dan lemak.

3. Air bekas mandi: Mengandung minyak dan lemak.

4. Air bekas cuci perabot: Mengandung padatan tersuspensi.

5. Air bekas cuci kendaraan bermotor: Mengandung minyak dan lemak.

\section{Diagram Alir dan Proses IPAL RW 11}

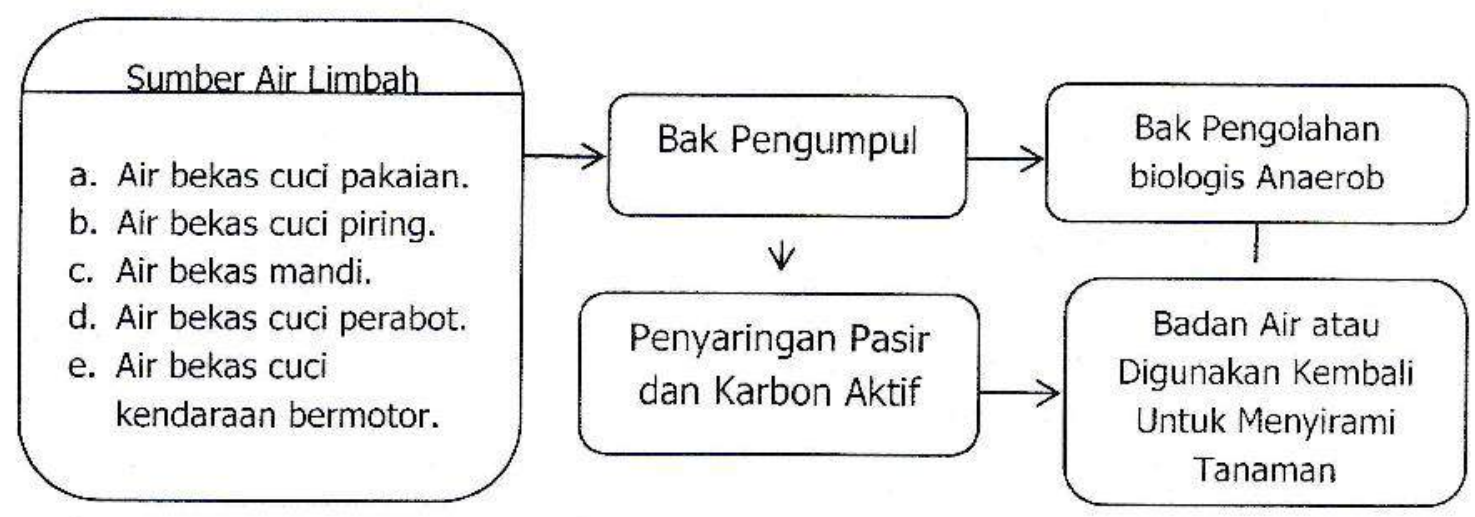

Gambar 1: Diagram Alir Pengolahan Air Limbah di RW 11 Kelurahan Kertajaya.

Sumber air limbah yang diolah pada IPAL RW 11 berasal dari air bekas cuci pakaian, air bekas cuci piring, air bekas mandi, air bekas cuci perabot, air bekas cuci kendaraan bermotor. Air limbah tersebut dialirkan melalui saluran pembuangan air limbah terbuka menuju ke bak pengumpul dan dilanjutkan ke bak pengolahan biologis anaerob. Setelah berada pada proses biologis, barulah air limbah disedot menggunakan pompa air untuk diteruskan ke penyaringan pasir dan karbon aktif dan 
selanjutnya dibuang atau digunakan untuk menyiram tanaman.

\section{Pengambilan contoh Air Limbah}

Pengambilan contoh/sampel air limbah dilakukan pada inlet dan outlet IPAL melalui pengulangan sebanyak tiga kali dengan menggunakan metode gabungan waktu, yaitu campuran contoh diambil dari satu titik pada waktu yang berbeda, dengan volume yang sama. Pengambilan contoh air limbah dilakukan pada hari Senin (pertama), Kamis (Kedua), dan Minggu (Ketiga). Pengambilan contoh air limbah dilakukan pada inlet dan outlet IPAL pada waktu siang hari, dan pengiriman contoh air limbah dilakukan langsung setelah pengambilan.

\section{Efisiensi Removal}

Efisiensi removal IPAL dapat dihitung setelah melakukan pemeriksa- an laboratorium. Efisiensi removal IPAL dihitung menggunakan rumus:

$$
\text { Efisiensi Removal }=\frac{A-B}{A} \times 100 \%
$$

\section{Dimana:}

$A=$ Hasil pemeriksaan sebelum pengolahan

$B=$ Hasil pemeriksaan setelah pengolahan

Efisiensi removal BOD pada tabel 3 menunjukkan efisiensi removal BOD sebesar $29,99 \%$ sampai $67,92 \%$. Sedangkan efisiensi removal COD pada tabel 4 menunjukkan efisiensi removal COD sebesar $8,524 \%$ sampai $44,606 \%$. Penurunan yang rendah ini diduga terdapat sedikitnya zat organik yang diolah oleh mikroorganisme dikarenakan waktu tinggal air limbah yang singkat. Seperti halnya yang dituliskan Asmadi dan Suharno (2012), semakin lama waktu tinggal dalam proses anaerob maka penyisihan yang terjadi akan semakin besar.

Tábel 3: PENURUNAN BOD SEBELUM DAN SESUDAH PROSES PENGOLAHAN

\begin{tabular}{|c|c|c|c|c|}
\hline \multirow{2}{*}{ No. } & \multirow{2}{*}{ Contoh/Sampel } & \multicolumn{2}{|c|}{$\begin{array}{c}\text { BOD } \\
\text { (mg/I) }\end{array}$} & \multirow{2}{*}{$\begin{array}{c}\text { Removal } \\
\text { (\%) }\end{array}$} \\
\cline { 3 - 4 } & & In/et & Out/et & \\
\hline 1. & Contoh I & 70,59 & 36,17 & 48,76 \\
\hline 2. & Contoh II & 81,48 & 26,14 & 67,92 \\
\hline 3. & Contoh III & 72,75 & 50,93 & 29,99 \\
\hline
\end{tabular}

Tabel 4: PENURUNAN COD AIR LIMBAH DOMESTIK SEBELUM DAN SESUDAH PROSES PENGOLAHAN

\begin{tabular}{|c|c|c|c|c|}
\hline \multirow{2}{*}{ No. } & \multirow{2}{*}{ Contoh/Sampel } & \multicolumn{2}{|c|}{ COD (mg/I) } & \multirow{2}{*}{$\begin{array}{c}\text { Removal } \\
\text { (\%) }\end{array}$} \\
\hline 1. & Contoh I & In/et & Out/et & 8,524 \\
\hline 2. & Contoh II & 98,414 & 90,025 & 44,606 \\
\hline 3. & Contoh III & 151,238 & 83,776 & 25,454 \\
\hline
\end{tabular}

Tabel 5: PENURUNAN KANDUNGAN TSS AIR LIMBAH DOMESTIK SEBELUM DAN SESUDAH PROSES PENGOLAHAN

\begin{tabular}{|c|c|c|c|c|}
\hline \multirow{2}{*}{ No. } & \multirow{2}{*}{ Contoh/Sampel } & \multicolumn{2}{|c|}{ TSS (mg/I) } & Removal \\
\cline { 3 - 5 } & & In/et & Outlet & $(\%)$ \\
\hline 1. & Contoh I & 16,00 & 4,00 & 75,00 \\
\hline 2. & Contoh II & 12,00 & 7,00 & 41,67 \\
\hline 3. & Contoh III & 26,00 & 2,00 & 92,31 \\
\hline
\end{tabular}

Efisiensi removal TSS pada tabel 5 menunjukkan efisiensi removal TSS sebesar $41,67 \%$ sampai $69,66 \%$. Penurunan TSS ini terjadi karena pada IPAL komunal milik RW 11 Kelurahan Kertajaya memiliki saringan pasir. Menurut Sugiharto (1987), penyaringan adalah pengurangan lumpur tercampur dan partikel koloid dari air limbah dengan melewatkan pada media yang porous. 
Tabel 6: PENURUNAN KANDUNGAN MINYAK DAN LEMAK AIR LIMBAH DOMESTIK SEBELUM DAN SESUDAH PROSES PENGOLAHAN

\begin{tabular}{|c|c|c|c|c|}
\hline \multirow{2}{*}{ No. } & \multirow{2}{*}{ Contoh/Sampel } & \multicolumn{2}{|c|}{ Minyak dan Lemak(mg/I) } & \multirow{2}{*}{$\begin{array}{c}\text { Removal } \\
\text { nyyn }\end{array}$} \\
\cline { 3 - 4 } & In/et & Outlet & 12,50 \\
\hline 1. & Contoh I & 6,40 & 5,60 & 61,90 \\
\hline 2. & Contoh II & 8,40 & 3,20 & 5,00 \\
\hline 3. & Contoh III & 12,00 & 11,40 & \\
\hline
\end{tabular}

Efisiensi removal Minyak dan Lemak pada tabel 6 menunjukkan efisiensi removal Minyak dan Lemak sebesar $5 \%$ sampai $61,90 \%$. Penurunan efisiensi yang rendah ini dikarenakan pada IPAL komunal milik RW 11 Kelurahan Kertajaya ini tidak memiliki bangunan/unit penangkap minyak dan lemak atau sering disebut dengan grease trap. Menurut Purwanto (2010), grease trap adalah unit pengolahan air limbah yang berfungsi untuk memisahkan lemak atau minyak. Lemak akan mengapung pada suhu $20^{\circ}$. Selanjutnya lemak yang terperangkap dibersihkan secara berkala dengan cara manual atau mekanik.

\section{Kualitas Air Limbah}

Data pada tabel 7 menunjukkan bahwa kualitas air limbah domestik yang telah diolah dan tidak memenuhi syarat pada parameter BOD, COD, dan Minyak dan Lemak.

Tabel 7: KUALITAS AIR LIMBAH SEBELUM DAN SESUDAH PROSES PENGOLAHAN

\begin{tabular}{|c|c|c|c|c|c|c|c|}
\hline \multirow[b]{2}{*}{ No } & \multirow[b]{2}{*}{ Unit } & \multirow[b]{2}{*}{ Parameter } & \multirow[b]{2}{*}{ Satuan } & \multicolumn{3}{|c|}{$\begin{array}{c}\text { Pengambilan Contoh Air Limbah } \\
\text { Domestik }\end{array}$} & \multirow{2}{*}{ 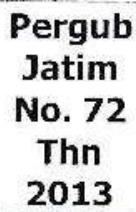 } \\
\hline & & & & $\begin{array}{c}\text { Contoh I } \\
19 \mathrm{Mei} \\
2014\end{array}$ & $\begin{array}{c}\text { Contoh II } \\
22 \mathrm{Mei} \\
2014\end{array}$ & $\begin{array}{c}\text { Contoh III } \\
25 \mathrm{Mei} \\
2014 \\
\end{array}$ & \\
\hline \multirow{5}{*}{1.} & \multirow{5}{*}{ Inlet } & $\mathrm{pH}$ & - & 7,21 & 7,06 & 7,10 & $6-9$ \\
\hline & & $\mathrm{BOD}$ & $\mathrm{mg} / \mathrm{l}$ & $70,59^{*}$ & $81,48^{*}$ & $72,75^{*}$ & 30 \\
\hline & & - $\mathrm{COD}$ & $\mathrm{mg} / \mathrm{l}$ & $98,414^{*}$ & $151,238^{*}$ & $143,526^{*}$ & 50 \\
\hline & & TSS & $\mathrm{mg} / \mathrm{I}$ & 16,00 & 12,00 & 26,00 & 50 \\
\hline & & $\begin{array}{l}\text { Minyak dan } \\
\text { Lemak }\end{array}$ & $\mathrm{mg} / \mathrm{l}$ & 6,40 & 8,40 & $12,00^{*}$ & 10 \\
\hline \multirow{5}{*}{2.} & \multirow{5}{*}{ Outlet } & $\mathrm{pH}$ & - & 7,54 & 7,51 & 7,36 & $6-9$ \\
\hline & & $B O D$ & $\mathrm{mg} / \mathrm{l}$ & $36,17^{*}$ & 26,14 & $50,93^{*}$ & 30 \\
\hline & & $C O D$ & $\mathrm{mg} / \mathrm{l}$ & $90,025^{*}$ & $83,776^{*}$ & $106,993 *$ & 50 \\
\hline & & TSS & $\mathrm{mg} / \mathrm{l}$ & 4,00 & 7,00 & 2,00 & 50 \\
\hline & & $\begin{array}{l}\text { Minyak dan } \\
\text { Lemak }\end{array}$ & $\mathrm{mg} / \mathrm{l}$ & 5,60 & 3,20 & $11,40^{*}$ & 10 \\
\hline
\end{tabular}

Keterangan: $\left(^{*}\right)$ Parameter yang tidak memenuhi baku mutu.

\section{KESIMPULAN}

1. Debit air limbah pada inlet adalah 30,81 $\mathrm{m}^{3} /$ hari dan debit air limbah outlet adalah 1,97 $\mathrm{m}^{3} /$ hari, yang artinya. kapasitas air limbah yang dihasilkan lebih besar dari pada kapasitas pengolahan IPAL, sehingga IPAL menjadi overflow.

2. Sumber air limbah warga RW 11 Kelurahan Kertajaya terdiri dari air bekas cuci pakaian, cuci piring, mandi, perabot, kendaraan bermotor.

3. Proses pengolahan air limbah di IPAL menggunakan metode biologis sistem anaerobik dan metode fisika yaitu filtrasi.
Efisiensi removal BOD sebesar 29,99\% sampai $67,92 \%$, COD sebesar $8,524 \%$ sampai $44,606 \%$, TSS sebesar $41,67 \%$ sampai $92,31 \%$, Minyak dan Lemak sebesar $5 \%$ sampai $61,90 \%$.

4. Parameter air limbah yang telah diolah memenuhi baku mutu dalam Peraturan Gubernur Jawa Timur Nomor 72 Tahun 2013 yaitu untuk parameter pH dan TSS. Sedangkan parameter air limbah yang telah diolah tidak memenuhi baku mutu dalam Peratutan Gubernur Jawa Timur Nomor 72 Tahun 2013 adalah pada 
parameter $\mathrm{BOD}$, COD, Minyak dan Lemak.

\section{SARAN}

1. Pengoperasian IPAL RW 11 Kelurahan Kertajaya sebaiknya dilakukan setiap hari agar tidak overflow.

2. Saluran pengumpul air limbah harus dibersihkan dari sampah dan pengerukan lumpur yang terendap di dasar saluran pengumpul.

\section{DAFTAR PUSTAKA}

Asmadi dan Suharno, 2012. Dasar-Dasar Pengolahan Limbah Cair. Yogyakarta, Gosyen Publising.

Badan Pembinaan Konstruksi, 2011. Materi Pelatihan Berbasis Kompetensi Sub Bidang Pengolahan Limbah dan Air Bersih Jabatan Kerja Pelaksana Lapangan Pekerjaan Bangunan Air Limbah Permukiman (Setempat dan Terpusat). Kementerian Pekerjaan Umum. Kode Unit Kompetensi TTL.PA25.264.00.

Djabu, Udin dkk, 1990/1991. Pedoman Bidang Studi Pembuangan Tinja dan Air Limbah Pada Institusi Pendidikan Sanitasi / Kesehatan Lingkungan. Jakarta, Departemen Kesehatan RI.

Fardiaz, S., 1992. Polusi Air \& Udara. Yogyakarta, Kanisius.

Mara, D. dan S. Cairncross, 1994. Pemanfaatan Air Limbah \& Ekskreta Patokan untuk Perlindungan Kesehatan Masyarakat. B. Matram (penterjemah). Bandung, ITB dan Universitas Udayana. Edisi Bahasa Indonesia.

Metcalf and Eddy, 1991. Wastewater Engineering treatment Disposal Reuse. McGraw-Hill Inc, New York. 2004. Wastewater Engineering, $4^{\text {th }}$ edition, Mc Graw Hill International Editions, New York.

Notoatmodjo, Soekidjo, 2005. Metodologi Penelitian Kesehatan Edisi Revisi. Jakarta, Rineka Cipta.
3. Dimensi bak pengumpul dan bak pengolahan biologis diperbesar sehingga waktu tinggal cukup dan efisiensi removal mencapai angka persen yang tinggi yaitu lebih dari $85 \%$.

4. Seharusnya dilakukan pemeriksaan laboratorium secara berkala kualitas efluen agar dapat mengetahui kinerja IPAL.
Nur'arif, M., 2008. Pengelolaan Air Limbah Domestik (Studi Kasus Di Kota Praya Kabupaten Lombok Tengah). Semarang, Universitas Diponegoro Semarang. eprints.undip.ac.id/18249/1/Muhamad Nu r'arif.pdf. Diakses pada tanggal 28 Februari 2014. Pukul 13.15 WIB.

Peraturan Gubernur Jawa Timur Nomor 72 Tahun 2013 Tentang Baku Mutu Air Limbah Bagi Industri Dan/Atau Kegiatan Usaha Lainnya.

Purwanto, D.S., 2010. Pengolahan Limbah Cair. Surabaya, Duatujuh. D.S., 2010. Pengelolaan Limbah Cair Teori Praktis Tenaga Sanitasi. Surabaya, Duatujuh.

Rochman, A., 2009. Pembuatan IPAL Mini Untuk Limbah Deterjen Domestik. Surabaya, Universitas Airlangga. www.journal.unair.ac.id/filerPDF/06\%20 vol $\% 207 \% 20$ no $\% 202 \% 20$ Agts $\% 202009$ $\% 20$ FST $\% 20$ faidur $\% 20$ rohman $\% 20125$ -133.pdf. Diakses pada tanggal 28 Februari 2014. Pukul 16.00 WIB.

Slamet, J.S., 1994. Kesehatan Lingkungan. Yogyakarta, Gadjah Mada University Press.

Sugiharto, 1987. Dasar-Dasar Pengelolaan Air Limbah. Jakarta, UI-Press. 